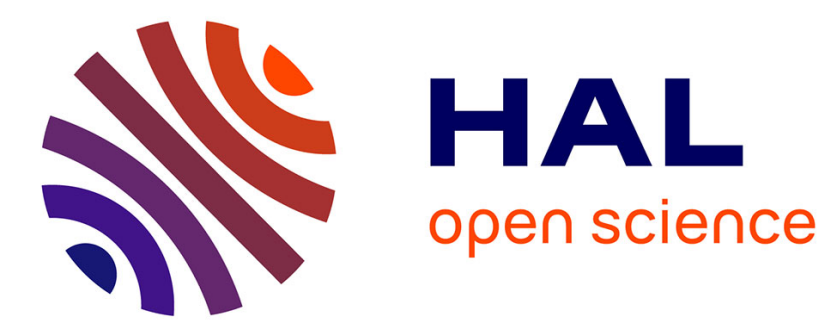

\title{
Does filtering by powered two-wheelers present a risk for pedestrians in city centers?
}

Nicolas Clabaux, Jean-Yves Fournier, Jean-Emmanuel Michel, Christophe Perrin

\section{- To cite this version:}

Nicolas Clabaux, Jean-Yves Fournier, Jean-Emmanuel Michel, Christophe Perrin. Does filtering by powered two-wheelers present a risk for pedestrians in city centers?. Journal of Transport and Health, 2019, 13, pp224-233. 10.1016/j.jth.2019.02.001 . hal-02127347

\section{HAL Id: hal-02127347 \\ https://hal.science/hal-02127347}

Submitted on 16 May 2019

HAL is a multi-disciplinary open access archive for the deposit and dissemination of scientific research documents, whether they are published or not. The documents may come from teaching and research institutions in France or abroad, or from public or private research centers.
L'archive ouverte pluridisciplinaire HAL, est destinée au dépôt et à la diffusion de documents scientifiques de niveau recherche, publiés ou non, émanant des établissements d'enseignement et de recherche français ou étrangers, des laboratoires publics ou privés. 


\title{
1 Does filtering by powered two-wheelers present a risk for pedestrians in 2 city centers?
}

Nicolas Clabaux*, Jean-Yves Fournier, Jean-Emmanuel Michel, Christophe Perrin

IFSTTAR (French Institute of Science and Technology for Transport, Development and Networks), TS2 (Transport, Health, Safety Department)-LMA (Laboratory of Accident Mechanisms Analysis), 304 Chemin de la Croix Blanche, F-13300 Salon de Provence, France

Keywords: powered two-wheelers, motorcycle, moped, pedestrian, filtering, crash

\begin{abstract}
Context: The increase in the use of powered two-wheelers (PTW) in large urban areas adds to the public debate on the question of legalizing the practice of filtering when traffic is congested. In recent years, filtering by PTW riders has been authorized in cities in several Australian States. In France, this practice has been authorized on an experimental basis since $1^{\text {st }}$ February 2016 on urban expressways, but for now it remains forbidden in city centers. Legalization and generalization of this practice in cities could, however, have a detrimental effect on pedestrian safety. The objective of the research presented in this paper is to estimate the risk for PTW riders of hitting and injuring a pedestrian per kilometer travelled while filtering and to compare this risk with that run while not filtering.

Method: Based on the detailed study of police reports recorded on 14 sections of urban arterials roads located in the city center of Marseille (France) and a campaign of periodical observations of powered two-wheeler practices, a relative risk and its $95 \%$ confidence interval are estimated.

Results: The results show that the practice of filtering is associated with a significantly higher risk of collision with a pedestrian compared to normal driving in the traffic flow. On the sections studied, the risk is 5.30 higher (95\% confidence interval [2.97; 9.43]). The main crash configurations are presented.

Conclusions: In cities, filtering practices by PTW have a deleterious effect on pedestrian safety. Countermeasures concerning the road layout or enforcement seem possible to mitigate this deleterious effect.
\end{abstract}

\section{Introduction}

Faced with transportation problems in metropolitan areas, powered two-wheelers (PTW) can provide an alternative way to travel and avoid getting stuck in congested traffic (Ducreux, 2008; Kopp, 2011). A strong increase in the use of these vehicles in congested metropolitan areas of Europe has been observed over the past twenty years (European Commission, 2013). This is largely due to their small size and good manoeuvrability, enabling their users to park their vehicle quickly, to thread through traffic and to filter when the traffic is congested, thus ensuring more regular travel times (Burge et al., 2007; Ducreux, 2008). In France, this filtering practice is still forbidden, at least in city centers. It is being tested on urban expressways in four metropolitan areas. This practice is starting to be legalized in some countries. In Belgium, since 2011, for example, motorcyclists can ride between traffic lanes going in the same direction when the vehicles in these lanes are stopped or moving slowly. This authorization applies to interurban environments as well as for urban environments ${ }^{1}$. In Australia, most of states (New South Wales ${ }^{2}$, Queensland ${ }^{3}$, Victoria ${ }^{4}$, South-Australia ${ }^{5}$ and Tasmania ${ }^{6}$ ) recently authorized filtering by motorcyclists in cities and elsewhere. When traffic speed is below $30 \mathrm{~km} / \mathrm{h}$,

\footnotetext{
${ }^{1}$ Royal decree of 11 June 2011 of 11 June 2011 aimed at promoting motorcycle safety and mobility, published the $20^{\text {th }}$ June 2011. http://www.ejustice.just.fgov.be (accessed 12 July 2018).

2 New South Wales Government. Road Transport Legislation Amendment (Lane Use by Motor Bikes) Regulation 2014. https://www.legislation.nsw.gov.au (accessed 12 July 2018).

${ }^{3}$ Queensland Government. Transport Operations (Road Use Management) https://www.legislation.qld.gov.au (accessed 12 july 2018).

4 Victorian Government. Road Safety Road Rules Amendment (Lane Filtering) Rules 2015. http://www.legislation.vic.gov.au (accessed 12 July 2018).

${ }^{5}$ South Australia Government. Road Traffic (Road Rules - Ancillary and Miscellaneous Provisions) Regulations 2014 - 1.6.2018. https://legislation.sa.gov.au (accessed 12 July 2018).

6 Road Safety Advisory Council, State of Tasmania. https://www.rsac.tas.gov.au/campaign/lane-filtering (accessed 12 July 2018).
} 
motorcyclists can ride between stationary or slow moving vehicles travelling in the same direction they are.

This is also a common demand from motorcyclist associations in many countries, who would like this current practice to be legalized.

However, it is a risky practice, first and foremost for PTW users themselves. Indeed, previous works have showed that, in large metropolitan centers, whatever the space used for filtering (bus lane, center of the roadway, space between traffic lanes going in the same direction) this practice is associated with an increased risk of injury (Clabaux, Fournier, Michel, 2017). Furthermore, this practice also appears to present risks for pedestrians, notably when they cross lanes where traffic is frequently congested. This is suggested by the conclusions of an experiment carried out in the center of Sydney prior to the legalization of the filtering practice in the State of New South Wales (Beanland et al., 2015). During this trial, which lasted eight weeks, motorcyclists were authorized to ride between lanes of cars stopped on five main streets in the city center. Camera observations of rider practices showed that filtering past stopped cars does not appear to pose any major safety problems for motorcyclists. On the other hand, it appears to raise safety problems for pedestrians: "safety risks posed by lane filtering were highest for pedestrians than any other road user group. [...] Concerns related to a perceived lack of familiarity with lane filtering, motorcyclists not giving way to pedestrians, and a lack of predictability of motorcyclist movement when lane filtering (where a pedestrian that crosses between stopped traffic, mid-block, might not think to look for a motorcycle moving through the lanes of traffic" (Transport for New South Wales, 2014; p.8).

Detailed crash studies also suggest that the weak cognitive conspicuity of PTW plays a major role in crashes involving a filtering PTW and a pedestrian (Clabaux et al., 2014a). In these crashes, the pedestrian's attention is often focused in a direction other than where the PTW is coming from. He/she may ignore the PTW coming from an unexpected direction. One crash of the "in-depth accident study" program carried out by IFSTTAR in the region of Salon de Provence, provides a good illustration of this point. In this case, the pedestrian was crossing a two-lane street and was hit in the middle of crossing by a scooter coming from the left and overtaking a line of stopped vehicles by the center of the roadway. Given the presence of a lane of stopped vehicles on the first part of his crossing, the pedestrian focused all his attention on the right side, toward the traffic coming from the opposite direction. He did not expect a scooter overtaking the line of stopped vehicles and did not detect the scooter before the collision. When the psychologist-investigator asked the question, "Where did you look while you were crossing?", the pedestrian answered: “At first I looked to the left to see if the cars were stopped. [...] After that I looked to the right at the oncoming cars because usually nobody comes from the left because the cars are stopped.”

On a sample of 24 cases involving a pedestrian and a filtering motorcyclist, Michel et al. (2016) also found that the pedestrian often did not expect the motorcyclist overtaking the stopped vehicles and was looking in the opposite direction before interacting with it. A study of these cases shows that another aspect plays a important role in these crashes: while driving alongside the stopped vehicles, motorcyclists become invisible for pedestrians crossing from the other side of the lane due to the line of vehicles itself blocking visibility between the protagonists.

Thus, the practice of filtering by PTW makes them hard to detect by pedestrians on the cognitive and sensorial levels.

For these different reasons, the legalization of filtering in cities could have a detrimental effect on pedestrian safety. This is what we have examined in this research. The objective was to estimate the risk (per kilometer traveled) of PTW users of hitting and injuring a pedestrian when they filter. The hypothesis that we sought to verify was that of an excess risk of collision with a pedestrian for PTW users when filtering.

\section{Material and methods}

Our investigations covered six years (from 2007 to 2012) and 14 sections of urban arterial roads, all located in the city center of Marseille. Marseille is one of twelve metropolitan areas in France. Located on the Mediterranean coast and enjoying a mild climate, there is widespread use of PTW. In the city center, for example, PTW represent $17 \%$ of traffic (Michel et al., 2013).

The sections covered by the study added up to $18 \mathrm{~km}$ of roads. Most of them were located on major arterial roads in the city of Marseille's road network (see Figure 1). They have a certain number of 
shared characteristics such as the presence of several lanes of traffic going in the same direction, intersections that usually have traffic lights, and the presence of dedicated bus lanes for most of them. Readers can view the Google Street View photos of these roads to get an idea of their layout and their environment. These sections were selected because we have precise traffic data for them. These data had been gathered as part of other studies dealing with the effects of the presence of bus lanes on pedestrian safety (see Fournier et al, 2016).

For each of the 14 sections studied, we first sought to estimate:

- the risk of PTW riders' hitting and injuring a pedestrian for each kilometer travelled while filtering and the 95\% confidence interval. For this, we compared the number of PTW riders involved in collisions with a pedestrian while filtering to the number of riders $\mathrm{x}$ kilometers traveled while filtering.

- likewise, the risk of PTW riders' hitting and injuring a pedestrian when they are not filtering and the $95 \%$ confidence interval.

In a second part, we have estimated a relative risk (RR) (and the 95\% confidence interval) for these two populations using the following formula:

$$
\mathrm{RR}=\frac{\text { (Number of PTW hitting a pedestrian while filtering) / (Number of PTW } \mathrm{xkm} \text { filtering) }}{\text { (Number of PTW hitting a pedestrian while not filtering) / (Number of PTW x km not filtering) }}
$$

A value of 1.20 , for example, means that the risk of hitting a pedestrian is $20 \%$ greater for filtering PTW than for those riding with the traffic flow.

Lastly, as the number of collisions is often relatively small and the results are rarely significant for each section, a relative risk common to all sections and its 95\% CI was calculated by performing a meta-analysis of data for the 14 sections (Elvik and Vaa, 2004). We assessed the possible statistical heterogeneity of the results between the sections using the DerSimonian and Laird's Q statistic (see Hasselbald and McCrory, 1995).

These investigations covered a period of 6 years (from 2007 to 2012), on weekdays plus Saturdays (excluding public holidays) and at the same times of day (from 6 am to $10 \mathrm{pm}$ ). It should also be pointed out that these investigations first covered all PTW categories taken together (motorcyclists and moped riders) and all filtering practices (notably lane splitting in the space between lanes of cars going in the same direction, but also filtering forward through the center of the roadway or through the bus lanes, which are the most widespread practices observed in France).

In order to discover how many PTW had hit and injured pedestrians on the sections studied between 2007 and 2012, we used police reports. Each police report involving a PTW and a pedestrian was studied in detail to determine whether the PTW was filtering or not at the time of the crash.

For risk exposure, i.e. the number of PTWs $\mathrm{x}$ kilometers traveled on these sections while filtering and while not filtering over the same periods, we used two additional data categories ${ }^{7}$ :

- First, the hourly traffic counted by electromagnetic loops installed at regular intervals on the road over the 2007 to 2012 period.

- Secondly, a campaign of powered two-wheeler traffic observations to determine the share of PTW in the total traffic and their filtering practices.

Concerning this second point, 56 hours of observations, including 28 rush hours (between 7 am and 9 am or between $4 \mathrm{pm}$ and $7 \mathrm{pm}$ ) and 28 non-rush hours, randomly distributed throughout the entire year of 2013 on the 14 sections, were carried out by the investigators positioned on the sidewalks. Each observation session lasted one hour. It should be noted that, during these observations, the investigators did not stay at one fixed point but constantly walked about at a slow pace throughout the section observed. This strategy was adopted due to the great volatility of the practice of filtering and in order to report on the practice of filtering for all sections and not just for one point in particular.

Cross-checking the results of these observations against the traffic data gathered by the electromagnetic loops in 2013 for the same days and at the same times, enabled us to estimate the

\footnotetext{
${ }^{7}$ It should be noted that no data on pedestrian exposure were available. Thus, it was not possible to estimate the risk for pedestrians to be hit by PTW during filtering manoeuvres or not.
} 
average share of PTW in total traffic. Applying this proportion to the traffic figures gathered by the electromagnetic loops on each section during each year studied (2007 to 2012) then enabled us to estimate the number of PTWs in circulation for each year and for each section. A similar approach was adopted to estimate the annual number of PTW that were filtering. The share of filtering PTW measured by the investigators on each section was applied to the total annual PTW traffic for the section. Likewise, the proportion of PTW observed that were not filtering was applied to the total annual PTW traffic for the section. To express the risk exposure in vehicles $\mathrm{x}$ kilometers, we took the annual number of powered two-wheelers filtering and those not filtering for each section and multiplied them by the length of the section.

\section{Fig 1. Map of studied sections}

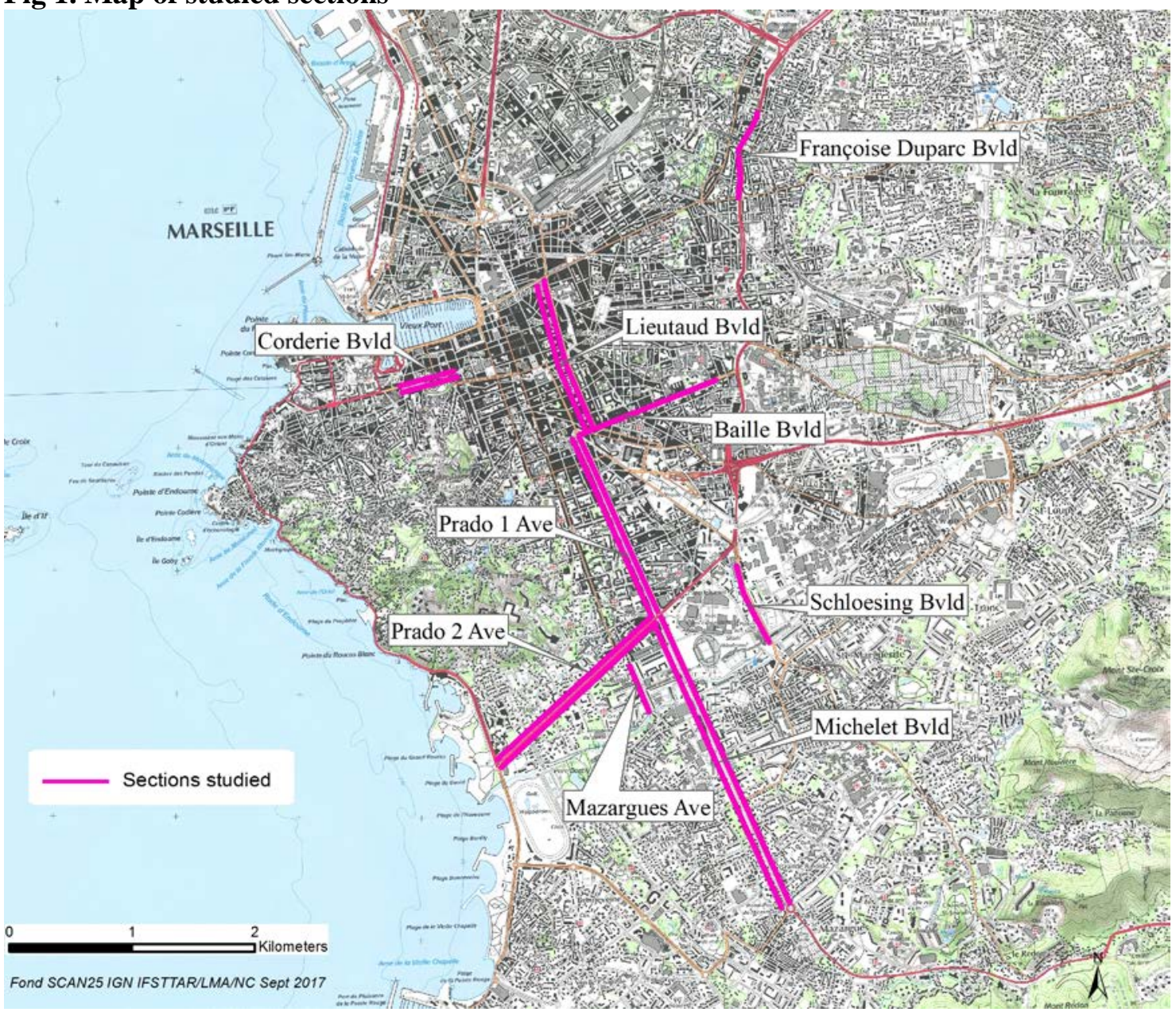

\section{Results}

During the years 2007 to 2012, there were 67 collisions involving a PTW and a pedestrian recorded by the police on the 14 sections during the periods studied. The detailed study of these cases enabled us to determine the PTW's maneuver at the time of the crash for 54 of them. Among these 54 cases, the PTW was filtering in 33 cases (or 61\%). It was not filtering in 21 cases. Three pedestrians were killed in these crashes, 1 in a collision with a filtering PTW and 2 by a PTW that was not filtering. Concerning risk exposure, exploitation of the traffic data from the electromagnetic loops and from the observations of powered two-wheeler traffic carried out throughout the year 2013 showed that, on average, powered two-wheelers accounted for $17.9 \%$ of the traffic on the 14 sections studied. According to our estimates, $20.7 \%$ of the kilometers ridden by powered two-wheelers annually on the sections studied are travelled while filtering. This proportion reaches $25.4 \%$ during rush hours and $169 \quad 17.8 \%$ in non-rush hour periods.

1703.1 Results relative to the validity of the risk exposure data Estimating the number of kilometers travelled by PTW while filtering and while not filtering using roadside observations may seem approximate and could lead to a biased estimate of the related crash 
risks. To verify the validity of the risk exposure data gathered in this way, an experiment was carried out on 4 of the 14 sections studied. The purpose was to determine the distances actually travelled while filtering and while not filtering over the total length of each section for a sampling of PTWs. The goal was to compare the results obtained during this experiment to the results obtained with the roadside observations. This experiment consisted in following and filming a sampling of motorcyclists all along the sections using a motorcycle equipped with a camera. For this, we equipped a Suzuki SV650 motorcycle with a Go Pro 4 portable camera (1920x1080 resolution) installed on the gas tank. The camera recorded the road scene as well as the instantaneous speed and the distance covered (within ten meters) displayed on an additional SIGMA MC10 counter that was precisely calibrated and positioned on the handlebars (see figure 2).

The motorcycle rider was an experienced rider. At the start of each observation sequence, he positioned himself at the start of the first section studied. An investigator told him which PTW to follow. It was chosen at random. The rider of this PTW did not know he was being filmed. The motorcyclist followed the PTW keeping as close as possible behind him (see the two examples presented in figure 2). At the end of the section, he went to a second investigator positioned at the start of the following section, who indicated another PTW to follow and so forth until he returned to the original starting point. The four sections put end-to-end make up a 5.3-km loop in the city center of Marseille. The images were analyzed afterwards by an operator using video analysis software (Kinovea). This was used to measure the proportion of the kilometers travelled over the section studied while filtering and while not filtering for each PTW monitored. These were then compared with the estimates from the roadside observations.

Fig 2. Screen captures from the video sequences from on-board observations
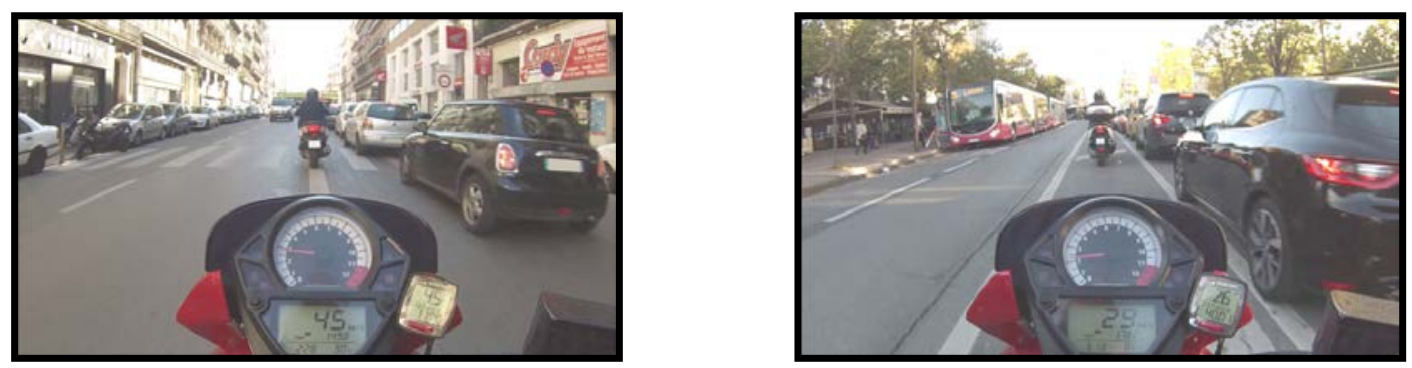

During the 4 half-days of observation, 141 powered two-wheelers were followed on the four sections. There was no significant difference between the proportions of mopeds, light motorcycles and heavy motorcycles filmed and the proportions of mopeds, light motorcycles and heavy motorcycles observed by the investigators on the roadside (see table 1 ).

The analysis of the 4 hour and 15 minutes of videos showed that the 141 two-wheelers rode 104 kilometers over the 4 sections studied.

Concerning filtering practices, table 2 presents the proportions of kilometers traveled while filtering by PTW filmed and the proportions of kilometers traveled while filtering by PTW observed on the roadside.

Table 1: Proportions of the different categories of powered two-wheelers during the on-board observations and during the roadside observations (same time periods, same sections)

\begin{tabular}{lccc} 
PTW categories & On-board observations & Roadside observations & $\boldsymbol{p}$ \\
\hline Mopeds & $14.2 \%$ & $17.2 \%$ & $N S$ \\
Light motorcycles & $44.7 \%$ & $42.8 \%$ & $N S$ \\
Heavy motorcycles & $41.1 \%$ & $40.1 \%$ & $N S$ \\
\hline
\end{tabular}

Table 2: Proportions of kilometers traveled by powered two-wheelers while filtering according to the on-board observations and to the roadside observations (same time periods, same sections) 


\begin{tabular}{lcc}
\hline PTW categories & $\begin{array}{c}\text { PTW followed and filmed } \\
\text { (on-board observations) }\end{array}$ & $\begin{array}{c}\text { PTW observed by investigators } \\
\text { (roadside observations) }\end{array}$ \\
\hline Mopeds & $18.5 \%$ & $22.9 \%$ \\
Light motorcycles & $14.9 \%$ & $24.2 \%$ \\
Heavy motorcycles & $19 \%$ & $29.6 \%$ \\
All PTW & $17.1 \%$ & $25.8 \%$ \\
\hline
\end{tabular}

Whatever the PTW category, the proportion of kilometers traveled while filtering among the PTW observed on the roadside appears to be higher. This difference is greater for motorcyclists. The proportions are closer for moped riders.

The detailed analysis of the results shows that it is mainly during non-rush hours that there is a major difference. According to the on-board observations, $14 \%$ of the kilometers ridden are travelled while filtering vs. $25.3 \%$ according to the roadside observations. During rush hours, the proportions are fairly close (20.7\% and $26.2 \%$, respectively).

In conclusion, the observations made on the roadside appear to slightly overestimate the share of kilometers traveled by PTW while filtering and to underestimate the share of their kilometers traveled while not filtering. The relative risks (risk of collision while filtering compared to the risk of collision while not filtering) presented in the rest of this article are therefore probably minima. Gathering risk exposure data with an equipped motorcycle would have provided more reliable estimates of the distances covered while filtering and while not filtering. Nonetheless, we did not use this method as it was too expensive and very time-consuming. For example, eight hours were needed to follow 141 PTWs, whereas the roadside investigators observed 8,261 PTW in 56 hours.

\subsection{Risks assessment results}

For each section, Table 3 presents the number of powered two-wheeler riders involved in collisions in terms of whether they were filtering or not, the estimate of the kilometers travelled by PTW riders while filtering and while not filtering and lastly, the estimate of relative crash risks and their 95\% confidence interval.

Table 3. Numbers of PTW riders collided with a pedestrian while filtering and while not filtering, estimate of the relative risks and the $95 \%$ CI for each section studied over the 20072012 period

2007-2012 Period

\begin{tabular}{|c|c|c|c|c|c|c|c|}
\hline Sections & $\begin{array}{l}\text { Nb of PTW } \\
\text { collided with } \\
\text { a ped. while }\end{array}$ & $\begin{array}{l}\text { Nb of PTW } \\
\text { collided } \\
\text { with a ped. }\end{array}$ & $\begin{array}{c}\text { PTW x km } \\
\text { travelled } \\
\text { while }\end{array}$ & $\begin{array}{c}\text { PTW x km } \\
\text { travelled } \\
\text { while not }\end{array}$ & $\mathbf{R R}$ & \multicolumn{2}{|c|}{$95 \%$ CI } \\
\hline $\begin{array}{l}\text { Bd. Schlœsing } \\
\text { (toward Rabatau) }\end{array}$ & 0 & 1 & 1190849 & 4090621 & 0.00 & - & - \\
\hline $\begin{array}{l}\text { Bd. Baille (toward } \\
\text { Castellanne) }\end{array}$ & 4 & 2 & 1758373 & 3964645 & 4.51 & 0.83 & 24.62 \\
\hline $\begin{array}{l}\text { Bd. Duparc (toward } \\
\text { Timone) }\end{array}$ & 4 & 0 & 2785903 & 1227614 & - & - & - \\
\hline $\begin{array}{l}\text { Bd. Michelet (toward } \\
\text { Mazargues) }\end{array}$ & 0 & 3 & 1220530 & 12516170 & 0.00 & - & - \\
\hline $\begin{array}{l}\text { Bd. Michelet (toward } \\
\text { Prado) }\end{array}$ & 3 & 2 & 1487909 & 9139799 & 9.21 & 1.54 & 55.1 \\
\hline $\begin{array}{l}\text { Bd. Corderie (toward } \\
\text { Corse) }\end{array}$ & 0 & 0 & 225609 & 986207 & - & - & - \\
\hline $\begin{array}{l}\text { Bd. Corderie (toward } \\
\text { the square) }\end{array}$ & 0 & 1 & 396064 & 1041519 & 0.00 & - & - \\
\hline $\begin{array}{l}\text { Av. Mazargues } \\
\text { (toward Prado 2) }\end{array}$ & 0 & 0 & 462324 & 1052235 & - & - & - \\
\hline Bd. Prado 1 (toward & 5 & 3 & 1516853 & 5195459 & 1.74 & 1.36 & 23.89 \\
\hline
\end{tabular}


Version postprint de l'article publié dans Journal of Transport and Health, Vol.13 (2019), pp 224-233

\begin{tabular}{lccccccc}
\hline Castellane) & & & & & & & \\
\hline $\begin{array}{l}\text { Bd. Prado 1 (toward } \\
\text { Michelet) }\end{array}$ & 7 & 1 & 1218354 & 5883482 & 33.80 & 4.16 & 274.76 \\
\hline $\begin{array}{l}\text { Bd. Prado 2 (toward } \\
\text { David) }\end{array}$ & 4 & 2 & 401819 & 4381582 & 21.81 & 3.99 & 119.07 \\
\hline $\begin{array}{l}\text { Bd. Prado 2 (toward } \\
\text { Michelet) }\end{array}$ & 2 & 0 & 409184 & 4730118 & - & - & - \\
\hline $\begin{array}{l}\text { Cours Lieutaud } \\
\text { (toward Canebière) }\end{array}$ & 1 & 2 & 1451772 & 3335626 & 1.15 & 0.10 & 12.67 \\
\hline $\begin{array}{l}\text { Cours Lieutaud } \\
\text { (toward Baille) }\end{array}$ & 3 & 4 & 1245628 & 2941296 & 1.77 & 0.40 & 7.91 \\
\hline All sections & $\mathbf{3 3}$ & $\mathbf{2 1}$ & & & $\mathbf{5 . 3 0}$ & $\mathbf{2 . 9 7}$ & $\mathbf{9 . 4 3}$ \\
\hline
\end{tabular}

The meta-analysis carried out on all the sections gave an overall relative risk of 5.30 (95\% CI [2.97; 9.43]). The heterogeneity test suggests that the trend observed can be considered as being common to all sections $(\mathrm{Q}=15.1 ; \mathrm{p}=0.30)$. During rush hours, the relative risk is 5.94 (95\% CI [2.72; 12.96]) and during non-rush hours, the relative risk is 4.21 (95\% CI [2.09; 8.50]).

Thus, PTW riders run a risk of hitting and injuring a pedestrian that is globally 5.3 times greater when filtering compared with driving with the traffic flow. Given what we observed previously, this is probably a minimum.

The same type of analysis was carried out for each PTW category. For this, we subdivided the overall crash sampling, which was already limited, leading to a loss of statistical power. For each PTW category, table 4 presents the relative risk of being involved in a collision with a pedestrian when filtering compared to the risk of being involved in a collision when not filtering. There does not appear to be any significant difference in the crash risk while filtering between the different PTW categories, although moped riders do seem to be over-involved compared to the other categories. When filtering, moped riders do indeed have a risk of collision with a pedestrian that 1.72 times greater $(95 \%$ CI [0.78; 3.79]) than the risk of light motorcycles and 1.96 times greater (95\% CI $[0.88 ; 4.36])$ than for heavy motorcycle riders. Filtering light motorcycle riders have a risk that is 1.16 times greater (95\% CI $[0.55 ; 2.47])$ than the risk for heavy motorcycles. But the confidence intervals contain the value of 1 in all cases.

Table 4. Relative risk of collision with a pedestrian in filtering situations between the different categories of PTW (14 sections, 2007-2012 period)

\begin{tabular}{lccc}
\hline & RR & \multicolumn{2}{c}{$\mathbf{9 5 \%} \mathbf{C l}$} \\
\hline Mopeds vs light motorcycles & 1.72 & 0.78 & 3.79 \\
Mopeds vs heavy motorcycles & 1.96 & 0.88 & 4.36 \\
Light motorcycles vs heavy & 1.16 & 0.55 & 2.47 \\
motorcycles & & & \\
\hline
\end{tabular}

Concerning the incidence of space used for filtering on crash risk, no matter which space is used, the risk of collision seems significantly higher compared with driving with the traffic flow. Table 5 presents the relative risks for the three main spaces used by PTW for filtering. Nevertheless, the results on this point are very weak due to the small number of collisions for each category.

Table 5. Relative risk of collision with a pedestrian in filtering situations for the different spaces used by PTW for filtering (14 sections, 2007-2012 period)

\begin{tabular}{lccc}
\hline & RR & \multicolumn{3}{c}{$\mathbf{9 5 \%} \mathbf{~ C l}$} \\
\hline Axis of the carriageway & 4.09 & 2.13 & 7.86 \\
Between traffic lanes & 8.14 & 1.37 & 48.4 \\
Bus lanes & 7.19 & 2.13 & 24.3 \\
\hline
\end{tabular}




\subsection{Results relative to the crash configurations}

Concerning the mechanisms at work in the crashes, figure 3 presents the three principal crash configurations observed among the 33 cases involving a pedestrian and a filtering PTW.

Figure 3. Principal crash configurations observed between a pedestrian and a filtering PTW (14 sections, 2007-2012 period)

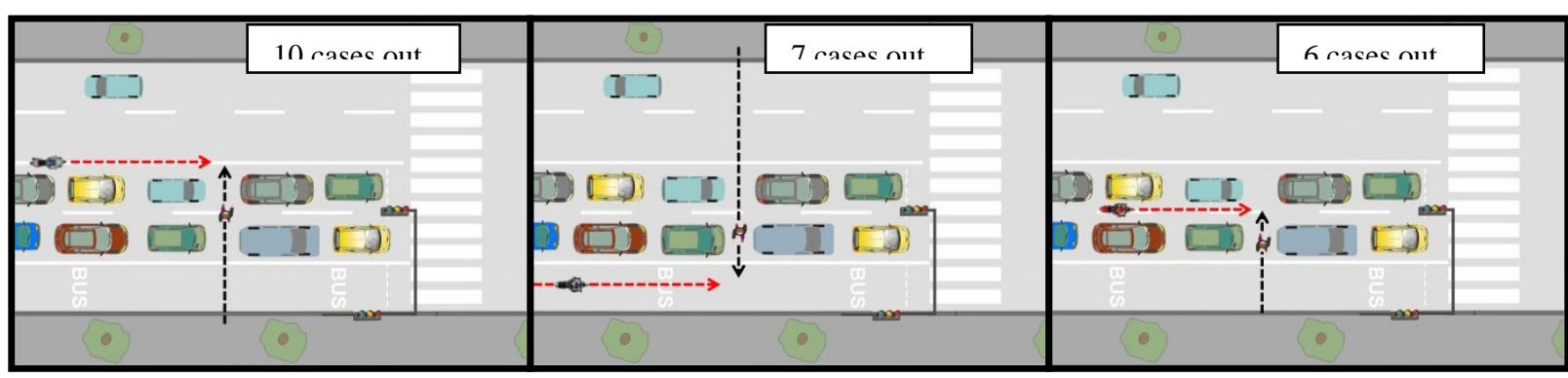

\section{Discussion and conclusions}

The results presented above suggest that, in cities, PTW filtering has a deleterious effect on pedestrian safety. Different interpretations can be proposed to explain the excess risk observed in filtering situations. First of all, it may be that not all PTW riders filter and those who filter have a more riskprone profile and less safe driving behaviors than those who do not filter. Thus, the excess risk observed could be explained not by filtering itself, but rather by the influence of confounding factors such as age, sex, experience, etc. The approach adopted does not enable us to adjust the results for these different cofactors. This interpretation should be taken with precaution, however, insofar as many PTW riders use this kind of vehicle to be able to thread through traffic and to filter (Burge et al., 2007). This is a widespread practice among PTW riders, sometimes even accounting for the majority of kilometers traveled, notably by commuters (Aupetit et al., 2015).

The excess risk could also be explained by the bigger number of pedestrian movements during rush hours, when filtering manoeuvres are more frequent. But the results have shown that both during rush hours and during non-rush hours, the risk of collision is significantly higher for PTW who filter.

The detailed study of crash cases suggests that the excess risk observed is also due to structural aspects. First of all, the fact that PTW ride alongside a lane of stopped vehicles makes them nearly invisible for pedestrians crossing from the other side of the stopped lane ${ }^{8}$. Secondly, the fact that they ride alongside a lane of vehicles that are stopped or nearly stopped at a small distance and at a relatively high speed ${ }^{9}$ also exposes PTW to not being able to avoid pedestrians or vehicles pulling out from behind one of the vehicles in the lane. Moreover the avoidance of the pedestrian is difficult because pedestrians often take advantage of the traffic slowdown or stoppage to run across the street. Among the 33 cases involving filtering PTW, 14 (i.e. 42\%) involved pedestrians running across the street. Thirdly, filtering also causes PTW to ride in areas of the roadway where they are cognitively hard to perceive for other users (Rogé et al., 2010), notably pedestrians. This can also be seen in pedestrians through their lack of seeking visual information in the PTW direction. The data used (police reports) did not enable us to demonstrate this, however.

The case analyses suggest that, for the PTW rider as well, the pedestrian's crossing was probably not particularly expectable, since among the 33 cases in which the pedestrian was hit by a PTW while filtering, 21 (i.e. 64\%) concerned pedestrians crossing outside pedestrian crosswalks.

Lastly, concerning the tendency of even higher crash risks for mopeds when filtering, it may be that this comes from the various risk factors that have already been identified in the literature, such as their young age (Aare \& Holst, 2003; Kopjar, 1999; Lardelli-Claret et al. 2005; Moskal, Martin \& Laumon, 2012), inexperience (Yannis, Golias \& Papadimitriou, 2005; SWOV, 2006, Blackman \& Haworth, 2013), or their greater tendency to intentionally disobey certain driving rules (Steg \& Van Brussel, 2009; Van Elslande \& Marechal, 2008;Wang et al., 2012) or to take risks (European Conference of

\footnotetext{
${ }^{8}$ It should be pointed out that, for PTW riders as well, pedestrians threading between stopped vehicles usually are not visible, either.

${ }^{9}$ According to the on-board observations, the average speed of PTW during filtering maneuvers was equal to $5 \mathrm{~km} / \mathrm{h}$ for the slowest and $62 \mathrm{~km} / \mathrm{h}$ for the fastest.
} 
Ministers of Transport (ECMT), 2000; Yannis et al., 2005; Brandau, Daghofer, Hofmann \& Spitzer, 2011). Although moped riders do not filter any more than other PTW categories, it may well be that they filter in a more risky way than other PTW categories due to these risk factors, but probably also due to their vehicle's greater maneuverability compared to motorcycles.

This research should be taken further, however, to delve more deeply in various points. First of all, the number of collisions studied did not enable us to obtain solid results concerning the risk related to the different spaces used by PTW when filtering (center of the roadway, space between lanes, bus lanes, notably). This is a central question in the debates on the legalization of filtering by PTW. Nor did the number of crashes enable us to obtain solid results for each PTW category or between categories. To make up for this problem, this research should be renewed, taking additional years into account.

The lack of data on pedestrian exposure did not enable us to obtain results concerning the risk for pedestrians to be hit by PTW during filtering manoeuvres or not. It's an other limitation of the study. Then, the method used to gather PTW's risk exposure data tended to slightly overestimate the proportion of kilometers traveled by PTW while filtering. The relative risks obtained are therefore minima. To get around this difficulty, one solution could be to undertake a data gathering campaign on risk exposure with the assistance of instrumented motorcycles. The approach adopted did not enable us to eliminate any possible influence by confounding factors in the excess risk observed. On this point, the use of multivariate analyses could be interesting. This would require stopping the motorcyclists observed to question them about their age, their experience, the kind of motorcycle used, etc.

Lastly, concerning the mechanisms at work in collisions between pedestrians and filtering PTW, the data used (police reports) did not enable us to validate the importance of the low cognitive conspicuity of the filtering PTW in these cases. Police reports do not provide sufficient information on the information-gathering strategies used by pedestrians when traffic is saturated. The use of in-depth investigations on these crash cases or of studies using pedestrian simulators (Cavallo et al., 2017), could be very useful on this point.

Despite these weaknesses, the results presented in this article suggest that all measures limiting filtering practices by PTW or at least the speed at which this is done would probably work toward improving pedestrian safety. This could, for example, lead to taking PTW and their practices more into account in the road layout. For example, a more systematic installation of pedestrian islands, notably at intersections with traffic lights where most filtering crashes occur, could be studied. Indeed, the presence of a pedestrian island could well keep a PTW from filtering or at least reduce its speed when doing so. However, no study has neither investigated the effect of pedestrian islands on filtering practice by PTW nor examined their incidence on collisions involving a pedestrian and a PTW. Pedestrian islands also enable pedestrians to cross in two stages and to concentrate on a single direction at a time. This can be useful during complex crossings on roads with several lanes going in both directions, such as those in question in this paper. Lastly, the pedestrian island protects the pedestrian from all possibility of collision with a vehicle and reduces exposure time to traffic. The installation of pedestrian islands usually comes with a feeling of greater safety for pedestrians (Yuan, 2009; Ni, Cao and Li, 2017), greater use of pedestrians crosswalks (channeling pedestrians into marked crosswalks) (Huang and Cynecki, 2000) and a decrease in the number of crashes (Elvik et al., 2009; Zegeer and Bushell, 2012; Zegeer et al., 2001). Nevertheless, such pedestrian islands may be harmful to motorcyclists in case of collision.

The study of filtering crash locations shows that a significant share of crashes that happen while filtering, occur outside the area of influence of intersections, mid-block. Other measures are therefore needed in these areas. A reduction in the number and width of traffic lanes and, more generally, the implementation of traffic-calming techniques and shared streets principles, could probably contribute to reducing the number of pedestrian/PTW collisions by reducing pedestrians' traffic exposure time and restricting PTW in their filtering practices (notably their speed). Such countermeasures also have generally recognized effects on pedestrian safety (see Brenac et al., 2003 and the references cited therein). Lane width also appears to have an influence on PTW decision to filter (see Haque et al., 2008; Vlahogianni, 2014).

These measures could be combined with better control of the use of bus lanes by PTW to avoid shifting filtering practices to bus lanes where they can take on even higher speeds. It should be pointed 
out that the use of bus lanes by PTW, sometimes mentioned as a way of improving their safety and their mobility (Kopp, 2011), is associated with an excess risk of collision (Clabaux et al., 2014b; York et al., 2010). Lastly, setting up barriers (pedestrian guardrails) at the main generators of pedestrian traffic flows, such as subway and bus stations, could be envisaged to channel pedestrian traffic flows toward pedestrian crosswalks. These systems are usually positive for pedestrian safety (Elvik et al., 2009; Retting et al., 2003). They can present risks, however, notably for child pedestrians who can be hidden from the PTW rider's view by the barriers (Stewart, 1988) and for PTW in cases of collision with barriers. Their installation can also appear in contradiction with shared space principles mentioned above which are increasingly used by urban planners and transportation engineers. Furthermore, other countermeasures like for example enforcement of filtering practices, could also constitute a promising way for limiting the deleterious effect of filtering by PTW on pedestrians safety.

\section{Aknowledgements}

The authors would like to thank Franck Lavergne and Marc Jouvenne of the Métropole Aix Marseille Provence. The work was realized with the support of the Agence Nationale de la Recherche, as part of the RED project.

\section{References}

Aare, M., \& Holst, H. (2003). Injuries from motorcycle and moped crashes in Sweden from 1987 to 1999. Injury Control and Safety Promotion, 10(3), 131-138.

Aupetit, S., Espié, S., Bouaziz, S. (2015). Naturalistic study of riders' behaviour in lane splitting situations. Cognition Technology and Work. 2015;17:301-313.

Beanland, V., Pammer, K., Sledziowska, M, Stone, A. (2015). Drivers' attitudes and knowledge regarding motorcycle lane filtering practices. Paper presented at: Proceedings of the first Australasian Road Safety Conference; October 14-16, 2015; Gold Coast, Australia.

Blackman, R. A., Haworth, N. (2013). Comparison of moped, scooter and motorcycle crash risk and crash severity. Accident Analysis and Prevention, 57, 1-9. http://dx.doi.org/10.1016/j.aap.2013.03.026.

Brandau, H., Daghofer, F., Hofmann, M., \& Spitzer, P. (2011). Personality subtypes of young moped drivers, their relationship to risk-taking behavior and involvement in road crashes in an Austrian sample. Accident Analysis and Prevention, 43(5), 1713-1719. http://dx.doi.org/10.1016/j.aap.2011.03.030.

Brenac, T., Nachtergaële C, Reigner H., (2003). Scénarios types d'accidents impliquant des piétons et éléments pour leur prévention. Rapport INRETS $n^{\circ} 256$. Institut National de Recherche sur les Transports et leur Sécurité, 207p.

Burge, P., Fox, J., Kouwenhoven, M., Rohr, C., Wigan, M.R. (2007). Modeling of motorcycle ownership and commuter usage: a UK study. Transportation Research Record. 2007;2031:59-68.

Cavallo, V., Dommes, A., Dang, N.T., Vienne, F., (2017). A street-crossing simulator for studying and training pedestrians. Transportation Research Part F: Traffic Psychology and Behaviour. In press. https://doi.org/10.1016/j.trf.2017.04.012

Clabaux N, Fournier J.Y, Michel J.E. (2014a) Powered two-wheeler drivers' risk of hitting a pedestrian in towns. Journal of Safety Research, 51, 1-5.

Clabaux, N., Fournier J.Y, Michel J.E. (2014b) Powered two-wheeler drivers' crash risk associated with the use of bus lanes. Accident Analysis and Prevention, 71, 306-310.

Clabaux N, Fournier J.Y, Michel J.E. (2017). Powered two-wheeler riders' risk of crashes associated with filtering on urban roads. Traffic Injury Prevention 18(2):182-187.

Ducreux, B.O (2008). Comparaison entre deux-roues à moteur et voitures : profil de conduite, consommation de carburant et émissions des gaz d'échappement en utilisation quotidienne. ADEME, Valbonne, 14p.

Elvik, R., Vaa, T., (2004). The handbook of road safety measures. Elsevier science, Amsterdam, 1078p.

Elvik, R., Høye, A., Vaa, T., Sørensen, M. (2009). The handbook of road safety measures. Second edition. Emerald Group Publishing Limited, 1124p. 
European Commission, (2013). Making roads safer for motorcycles and mopeds. Available at: http://ec.europa.eu/transport/road_safety/users/motorcyclists-mopdeds/index_en.htm. Accessed $18^{\text {th }}$ july 2018.

European Conference of Ministers of Transport (ECMT) (2000). Safety in road traffic for vulnerable road users. Paris: OECD Publishing. http://dx.doi.org/10.1787/9789264181571-en, 112p.

Fournier, J.Y., Clabaux, N., Brenac, T., (2016). Sécurité des piétons dans les rues équipées de couloirs réservés aux bus. Recherche Transports Sécurité vol.124-125, 27-42.

Haque, M.M., Hoong Chin, H., Huang, H.L. (2008). Examining exposure of motorcycles at signalized intersections. Transportation Research Record, 2048, 60-65.

Hasselbald, V., McCrory, D.C. (1995). Meta-analytic tools for medical decision making: a practical guide. Medical Decision Making, 15:81-96.

Huang, H.F., Cynecki, M.J., (2000). Effects of Traffic Calming Measures on Pedestrian and Motorist Behavior. Transportation Research Record 1705, Paper No. 00-0443., pp. $26-32$.

Kopjar, B. (1999). Moped injuries among adolescents: A significant forgotten problem. Accident Analysis and Prevention, 31(5), 473-478. http://dx.doi.org/10.1016/S0001-4575(98)00085-2.

Kopp, P., (2011). The unpredicted rise of motorcycles: A cost benefit analysis. Transport Policy, Volume 18, Issue 4, August 2011, 613-622.

Lardelli-Claret, P., Jiménez-Moleón, J.J., de Dios Luna-del-Castillo, J., Garcia-Martin, M. (2005). Driver dependent factors and the risk of causing a collision for two wheeled motor vehicles. Injury Prevention, 11, 225-231. http://dx.doi.org/10.1136/ip.2004.006957.

Michel, J. E., Fournier, J. Y., Clabaux, N. (2013). Place des deux-roues motorisés dans la circulation urbaine: une étude observationnelle. Transport Environnement Circulation, 217, 58-61.

Michel, J.E., Clabaux, N., Fournier, J.Y. (2016). Scénarios types d'accidents impliquant un motocycliste et un piéton. Actes du colloque "Des piéton.nes et des villes: connaissances, enjeux, culture de la marche”. 11-13 juil. 2016, Université Paris-Sorbonne - Paris (France), L’Harmattan, in press).

Moskal, A., Martin, J. L., Laumon, B. (2012). Risk factors for injury accidents among moped and motorcycle riders. Accident Analysis and Prevention, 49, 5-11. http://dx.doi.org/10.1016/j.aap.2010.08.021.

Ni, Y., Cao, Y., Li, K. (2017). Pedestrians' Safety Perception at Signalized Intersections in Shanghai. World Conference on Transport Research - WCTR 2016 Shanghai. 10-15 July 2016. Transportation Research Procedia 25, 1955-1963.

Orfeuil, J.P. (2012). L'explosion des deux-roues motorisés dans le monde : paradis ou enfer ? Urbanisme, vol.385, 45-46.

Retting, R.A., Ferguson, S.A., McCartt, A.T. (2003). A review of evidence-based traffic engineering measures designed to reduce pedestrian-motor vehicle crashes. American Journal of Public Health, Vol. 93(9), 1456-1463.

Rogé, J., Ferretti, J., Devreux, G., (2010). Sensory conspicuity of powered two-wheelers during filtering manoeuvres, according the age of the car driver. Le Travail Humain. 2010;73:7-30.

Steg, L., \& Van Brussel, A. (2009). Accidents, aberrant behaviours, and speeding of young moped riders. Transportation Research Part F: Traffic Psychology and Behaviour, 12, 503-511. http://dx.doi.org/10.1016/j.trf.2009.09.001.

Stewart, D. (1988). Pedestrian guard rails and accidents. Traffic Engineering Control, 29, 450-455.

SWOV (Institute for Road Safety research) (2006). Young moped riders. SWOV fact sheet. Leidschendam, The Netherlands: Institute for Road Safety Research, 5p.

Transport for New South Wales (2014). Motorcycle lane filtering trial. Summary of trial results. Centre for road safety. April 2014, 15p.

Van Elslande, P., \& Marechal, M. (2008). Accidentologie des cyclomoteurs. Rapport de convention INRETS/La prévention routière. Bron: Institut National de Recherche sur les Transports et leur Sécurité, 81 p.

Vlahogianni, E.I. (2014). Powered-two-wheelers kinematic characteristics and interactions during filtering and overtaking in urban arterials. Transportation Research Part F: Traffic Psychology and Behaviour;24:133-145. 
Wang, X., Xu, Y., Tremont, P. J., \& Yang, D. (2012). Moped rider violation behavior and moped safety at intersections in China. Transportation Research Record, 2281, 83-91. http://dx.doi.org/10.3141/2281-11.

Yannis, G., Golias, J., \& Papadimitriou, E. (2005). Driver age and vehicle engine size effects on fault and severity in young motorcyclists accidents. Accident Analysis and Prevention, 37(2), 327-333. http://dx.doi.org/10.1016/j.aap.2004.10.003. York I, Ball S, Anjum O, Webster D. (2010). Assessment of TfL's Experimental Scheme to Allow Motorcycles onto With-flow Bus Lanes on the TRLN. Crowthorne, UK: Transport Research Laboratory; 2010. Final Project Report PPR 495. Yuan, A., Chen, Y., Guo, J., Meng, H., Wang, S., (2009). GRSI Beijing project of improving vulnerable road users (VRU) safety at intersections. Road safety data: collection and analysis for target setting and monitoring performance and progress., pp. 263-273. Zegeer, C.V., Bushell, M., (2012). Pedestrian crash trends and potential countermeasures from around the world. Accident Analysis and Prevention, 44, 3-11. Unmarked Crosswalks at Uncontrolled Locations: Analysis of Pedestrian Crashes in 30 Cities. Transportation Research Record: Journal of the Transportation Research Board, 1773, 56-64. 